DOI: https://doi.org/10.24867/02BE31Zivkovic

\title{
PRISTUP NADGLEDANJU INDIKATORA RADA IOT ČVORIŠTA U REALNOM VREMENU
}

\section{ACCESS TO MONITORING INDICATOR OF WORKING OF IOT HUB IN REAL TIME}

\author{
Dejan Živković, Fakultet tehničkih nauka, Novi Sad
}

\section{Oblast - Upravljanje sistemima}

Kratak sadržaj - U ovom radu opisano je proširenje programske podrške postojećeg sistema kućne automatizacije. Proširenje podrazumijeva dodavanje kontrolera, u vidu novog modula, koji će prikupljati trenutnu statistiku rada sistema. To se odnosi na prikupljanje informacija o broju promjena stanja uređaja $i$ broju aktivacija scena u sistemu. Takođe, kontroler implementira $i$ opciju za podešavanje vremenskog intervala u toku kojeg će statistika biti prikupljana. Dat je i kratak opis IoT tehnologije, koja se koristi u opisanom programskom rješenju za spregu kućnih uređaja sa „oblak" računarskim sistemom, radi bolje i kvalitetnije analize podataka i informacija o radu sistema.

Ključne reči: Sistemi kućne automatizacije, IoT, „oblak“ računarstvo

\begin{abstract}
This paper describes the expansion of software support for the existing home automation system. Extension implies the addition of a controller in the form of a new module that will collect current system operating statistics. This refers to the collection of information about the number of changes in the condition of the device and the number of activations of the scenes in the system. Also, the controller implements the option to set the time interval during which the statistics will be collected. Also, there is short description of IoT technology used in the described software solution for interconnecting home appliances with a "cloud" computer system, for better and quality data analysis and information on system operation.
\end{abstract}

Keywords: Home automation systems, IoT, "cloud" computing

\section{UVOD}

Sistem kućne automatizacije je tehnološko rješenje koje obuhvata automatizaciju većine elektronike, električnih i tehnoloških funkcija u kući. Upotrebljava kombinaciju hardverskih i softverskih rješenja koje omogućavaju kontrolu i upravljanje aparatima i uređajima u kući. Kuća sa sistemom automatizacije se naziva „pametna kuća“. Uređaji unutar sistema kućne automatizacije se povezuju i komuniciraju međusobno preko lokalne (LAN) ili bežične mreže.

\section{NAPOMENA:}

Ovaj rad proistekao je iz master rada čiji mentor je bio dr Velimir Čongradac, vanred. prof.
Čitav sistem kućne automatizacije zahtjeva programsku podršku za upravljanje sistemom, instalaciju kontrolera za uređaje i aparate, senzore temperature i pokreta, kao i druge komponente [1].

Internet stvari (eng. Internet of Things) ili skraćeno IoT, je mreža fizičkih objekata ili „stvari“, ukomponovanih sa softverom, elektronikom, senzorima i mrežnom spregom, koja omogućava ovim objektima da sakupljaju i razmjenjuju podatke.

Pametna kuća je primjena internet tehnologija $\mathrm{u}$ domaćinstvu. Kombinuje prikupljanje, komunikaciju, skladištenje i analizu podataka, softverski i električni dizajn, grupu tehnologija, kao što su čuvanje energije i zaštita okoline. IoT omogućava da se vrijednosti objekata očitaju sa senzora $\mathrm{i}$ da se kontrolišu udaljeno preko postojeće mrežne infrastrukture.

To otvara mogućnost za neposredniju integraciju između stvarnog svijeta i računarskih sistema i rezultuje povećanom efikasnošću, preciznošću i ekonomskom dobiti. Svaka „stvar“ je jedinstveno identifikovana preko svog ugrađenog računarskog sistema, ali može i da razmjenjuje informacije sa drugim komponentama postojeće internet infrastrukture [2].

\section{INTERNET STVARI (IoT)}

IoT može da se definiše kao mreža povezanih uređaja sa jedinstvenim identifikatorima u obliku IP adrese, koji imaju ugrađene tehnologije ili su opremljeni tehnologijama koje im omogućavaju da prikupljaju informacije sa senzora $\mathrm{i}$ da komuniciraju međusobno $\mathrm{i} / \mathrm{ili}$ sa okolinom u kojoj se nalaze.

Potencijal i realnost IoT-a se ne ogleda u povezanosti IoT objekata niti u ugrađenoj tehnologiji i elektronici, kao što su senzori, aktuatori i mogućnosti povezivanja. Ogleda se $\mathrm{u}$ načinu na koji se IoT koristi da bi unaprijedio uvid $\mathrm{u}$ podatke, da automatizuje, digitalizuje, optimizuje i u zrelijim fazama transformiše procese, poslovne modele pa čak $\mathrm{i}$ industrijskih procesa $\mathrm{u}$ pogledu digitalne transformacije.

Nisu svi mrežno povezani uređaji IoT povezani, ali su svi IoT uređaji mrežno povezani. Šta više, u IoT se koristi IP protokol, preciznije IPv6. Stoga, o IoT se može govoriti samo ako su ,stvari““ jedinstveno adresibilne, preko IP adrese ili URI-ja (Uniform Resource Identifier). IoT ne čine samo povezani uređaji, nego i hardver, softver, mrežni i komunikacioni protokoli, kao i mnoga toga drugog potrebnog za kreiranje IoT rješenja [3]. 


\subsection{Prikupljanje podataka u sistemu kućne automatizacije}

Pametna kuća je virtuelno-fizički sistem izgrađen na IoT, računarima i pametnim kućnim aparatima, sa ljudskom interakcijom preko kućnih komunikacionih mreža i interneta. Kao sakupljač podataka i pristupnik internetu, mrežni prolaz (eng. gateway) pametne kuće nadgleda uređaje pametne kuće koji kontrolišu kućno okruženje i služe korisnicima. Tradicionalno, mrežni prolaz, npr. modem ili ruter, povezuje internet konekciju sa kućnom lokalnom mrežom. Takođe, upravlja mrežom za većinu kućnih mrežnih uređaja, kao što su pametni telefoni, pametni električni aparati i dr. [4]. Na slici 1 je prikazan jednostavan dijagram prikupljanja podataka u sistemu kućne automatizacije koji se oslanja na IoT. prikazan Kućni IoT uređaji, kao što su pametni ormarići, video nadzor, daljinski kontroleri i slično, su povezani preko različitih komunikacionih tehnologija da bi obezbjedili različite tipove pametnih aplikacija, uključujući nadzor okoline, bezbjednost, kućnu automatizaciju...[5]. Cjelokupno mrežno upravljanje ovim kućnim aplikacijama se odvija u pametnom mrežnom prolazu, tzv. gejtveju. On takođe sarađuje sa spoljnim sistemima, poput „oblak“ (eng. cloud) i internet servisa. Da bi se obezbjedili mrežni servisi sa dobrim kvalitetom ličnog iskustva korisnika (eng. quality-of-experience), ili skraćeno QoE, pametni gejtvej mora da prikupi ogromnu količinu podataka za analizu, npr. u „oblaku“. Analiza podataka će se usredsrediti na podatke o mjerenjima mrežnog kvaliteta servisa (eng. quality-of-service), ili skraćeno QoS, bezbjednosti i ponašanju korisnika pametne kuće [6].

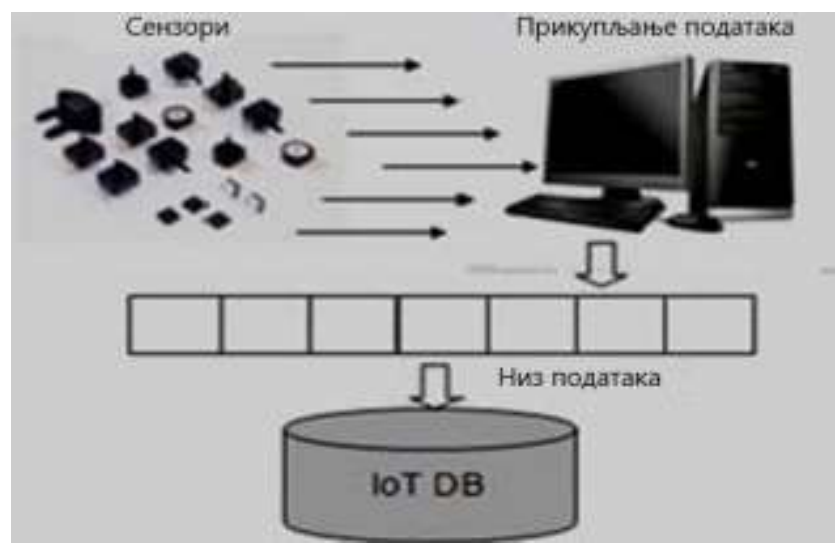

Slika 1. Dijagram prikupljanja podataka sistema kućne automatizacije baziranog na IoT [4]

\section{KONCEPT RJEŠENJA}

Postojeće rješenje se sastoji od 3 komponente i to:

Softverske komponente koja obezbjeđuje funkcionalnosti kućne automatizacije, nazvane „kućni upravljač“;

„Oblak“ servis koji povezuje krajnje korisnike sa njihovim domom bilo gdje da se nalaze;

Klijentske aplikacije koje omogućavaju krajnjim korisnicima da kontrolišu svoje domove sa Android, IoS ili uređajima baziranim na mrežnom pretraživaču.

Kućni upravljač radi ili na gejtvej uređaju kućne automatizacije ili se integriše unutar programskog okruženja uređaja „domaćina“ (npr. WiFi/3G/4G ruter, zvučna karta, personalni računar i dr.). Podržava najmodernije bežične komunikacione protokole danas, kao što su Zigbee, Z-Wave, IP. Kreira univerzum u kojem su sva čvorišta apstraktna u odnosu na svoje usluge i svojstva. Podržava jednostavnu integraciju novih protokola kućne automatizacije, koristi javni aplikativni programski interfejs (API), podržava konfiguraciju preko mrežnih interfejsa, upravlja čvorištima pomoću lokacije ili tipa, podržava napredne mehanizme scena, povezuje se na „oblak“ servise preko MQTT protokola i omogućava pristup nekim funkcijama „oblak“ servisa, poput daljinskog upravljanja, dijagnostike, ažuriranja firmvera $i$ slično.

„Oblak“ servis omogućava kontrolu domaćinstva izvan lokalne mreže i dozvoljava udaljenu dijagnostiku i konfiguraciju raspoređenih gejtveja kućne automatizacije. Može da se koristi kao kompletno „oblak“ rješenje ili da se integriše sa postojećim „oblak“ servisom. Zasnovan je na novoj mrežnoj tehnologiji, poznatoj kao MQTT, obezbjeđuje najveću bezbjednost i robusnost sa najmanjim kašnjenjem u komunikacionom lancu kućne automatizacije. Ključne komponente rješenja su aplikativni server, baza podataka i pozadinski servisi. Cjelokupna komunikacija je bazirana na sigurnim protokolima. Dodatna mjera bezbjednosti je ta što se gejtveji uvijek povezuju na predefinisanu adresu na „oblaku“ koja se ne može mijenjati.

Klijentske aplikacije obezbjeđuju finu kontrolu doma pomoću aplikacija lakih za upotrebu. Ključna ideja je da se sakrije složenost tehnologije od korisnika iza grafičkog korisničkog interfejsa (GUI). Aplikacije u svakom trenutku imaju najažurnije informacije o gejtvejima i čvorištima.

U cilju proširenja postojećeg rješenja potrebno je realizovati kontroler u okviru „kućnog upravljača“ koji će pratiti rad internih modula $i$ na osnovu prikupljenih informacija davati statistiku o radu sistema. Potrebno je da kontroler prati broj ažuriranja uređaja u sistemu i broj izvršavanja scena. To podrazumijeva ukupan broj ažuriranja uređaja, odnosno izvršavanja scena, od početka rada sistema i prosječan broj ažuriranja uređaja, odnosno izvršavanja scena, u jedinici vremena. Podešavanje kontrolera treba da omogući opciju za podešavanje jedinice za prosječan broj izvršavanja na svakih 15 minuta, 30 minuta i na svakih sat vremena

Pored opcije za podešavanje, kontroler treba da omogući skup funkcija za dobavljanje statistike: za sve uređaje, za 
sve scene i dobavljanje statistike po uređaju i po sceni. U daljem dijelu teksta biće opisana implementacija svake od navedenih funkcionalnosti kontrolera pojedinačno.

\subsection{Dobavljanje statistike za uređaje}

Uređaji u sistemu su razni senzori, kao što su dimer, senzor prisustva, svjetlosni senzor, pametna utičnica itd. Svi su jednoznačno određeni svojim identifikatorom na mreži (ID), nazivom servisa, nazivom svojstva i vrijednošću uređaja. ID predstavlja jedinstveni identifikator uređaja, na osnovu kojeg se uređaj razlikuje od ostalih na mreži. Naziv servisa je vrsta usluge koju dati senzor nudi (svjetlosni senzor, pametna utičnica i dr.). Naziv svojstva predstavlja svojstvo koje nudi dati servis (za svjetlosni senzor može biti status, da li je uključen ili isključen i sl.). Vrijednost uređaja može da se mijenja neposredno (npr. pritiskom na prekidač pametne utičnice) ili posredno (preko android klijentske aplikacije).

Svaka promjena neke od ovih osnovnih informacija o uređaju smatra se događajem. Kad se desi promjena, nove vrijednosti se pokupe i skladište se u listu događaja. Kad se od kontrolera zatraži informacija o promjeni stanja određenog uređaja, kontroler dobavlja broj promjena stanja uređaja sa traženim identifikatorom, nazivom servisa i nazivom svojstva. To radi tako što prođe kroz listu događaja i provjeri da li se tražene vrijednosti poklapaju sa onima u listi, i za svako poklapanje uveća brojač promjena stanja uređaja. Ukupan broj promjena za traženi uređaj se nakon toga proslijedi klijentskoj aplikaciji koja je uputila upit. Na slici 2 prikazan je algoritam dobavljanja statistike za uređaje.

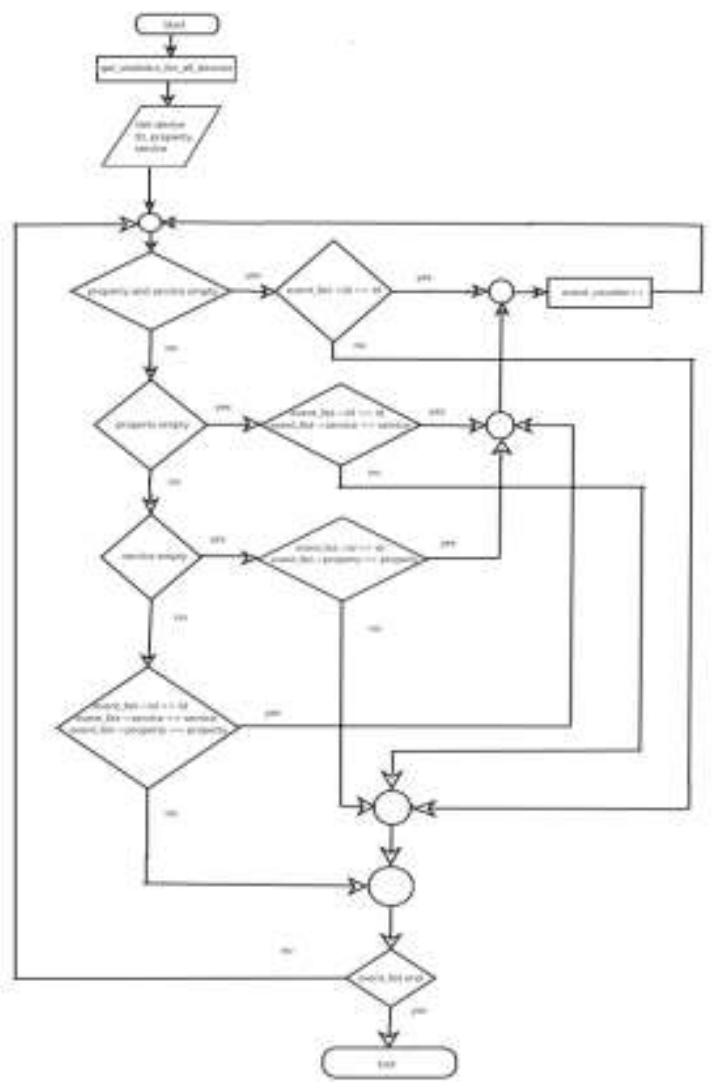

Slika 2. Algoritam dobavljanja statistike promjena stanja uređaja

\subsection{Dobavljanje statistike za scene}

Scenario predstavlja način na koji uređaji sistema kućne automatizacije sarađuju jedni sa drugima i sa korisnikom. $\mathrm{Na}$ primjer, scenario može biti „upali svjetlo“, ili ,provjeri zauzetost prostorije i ako je prostorija prazna 2 minuta, ugasi svjetla u toj prostoriji“.

Scene predstavljaju funkcije koje omogućavaju korisniku da kreira različite scenarije, čineći time domaćinstvo pametnijim. Mogu da integrišu više uređaja u sistemu i mogu da se aktiviraju vremenskim uslovima, tajmerima ili raznim stanjima senzora ili drugih modula [34]. Scene su jednoznačno određene svojim identifikatorom, na osnovu koga se razlikuju u sistemu.

Svaka aktivacija scene se prati i identifikator promjenjene scene se skladišti u listu scena. Kad se zatraži od kontrolera promjena scene sa datim identifikatorom, prolazi se kroz listu scena i uvećava se brojač promjena scena za svako poklapanje traženog identifikatora scene sa identifikatorom scene iz liste. Rezultat se vraća korisničkoj aplikaciji, koja je uputila upit. Slika 3 ilustruje algoritam dobavljanja statistike aktivacija scena.

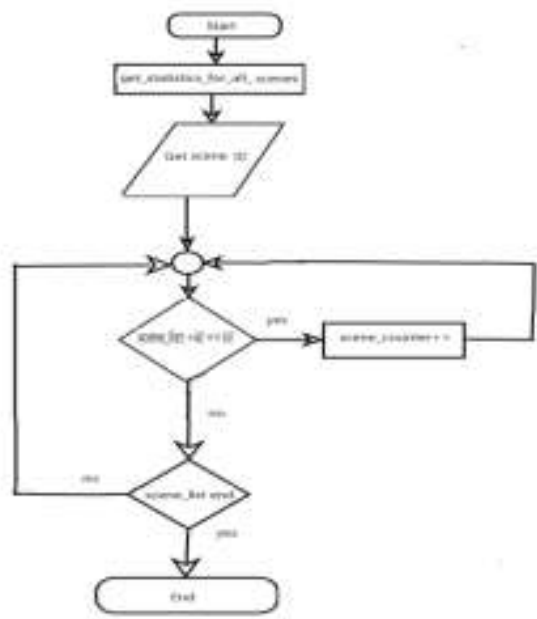

Slika 3. Algoritam dobavljanja statistike za scene

\subsection{Dobavljanje statistike za uređaje i scene u jedinici vremena}

Da bi se dobavljala statistika uređaja i scena $u$ jedinici vremena, implementirana je opcija za podešavanje kontrolera. Ona ima 3 moguće vrijednosti; 0,1 i 2 , od kojih opcija 0 podešava vremenski interval dobavljanja statistike na 15 minuta, opcija 1 na 30 minuta, a opcija 2 na sat vremena. Opcija se u vremenski interval konvertuje pomoću funkcije fromEpochTime() Poco biblioteke, o čemu će više riječi biti u sljedećem poglavlju. Konvertovana vrijednost intervala se prosljeđuje kao dodatni parametar funkcijama za dobavljanje statistike promjena stanja uređaja i scena. Takoće, u listu događaja se, pored identifikatora uređaja, naziva servisa i naziva svojstva, dodaje i zadati vremenski interval. Isto tako, u listu scena, pored identifikatora scene, se dodaje i zadati vremenski interval. Vrijednost intervala se zatim poredi sa trenutnim vremenom rada sistema i ako je vrijednost intervala manja, vrši se dobavljanje statistike od početka rada sistema, a ako je veća, pravi se vremenski prozor $\mathrm{u}$ vrijednosti zadatog intervala $u$ kojem se dobavlja 
statistika. Na primjer, ukoliko se iz korisničke aplikacije zada opcija 0, vršiće se prikupljanje statistike u vremenskom prozoru od 15 minuta. Ukoliko je ta vrijednost zadata u prvih 15 minuta rada sistema, vršiće se dobavljanje statistike od početka rada sistema. Ukoliko se vrijednost intervala zada nakon 15 minuta rada sistema, trenutak u kome se zada vrijednost, smatra se početnim trenutkom dobavljanja statistike, i od tog trenutka pa $\mathrm{u}$ narednih 15 minuta će se vršiti dobavljanje statistike. $\mathrm{Na}$ slici 4 prikazan je algoritam dobavljanja statistike $u$ zadatom vremenskom intervalu.

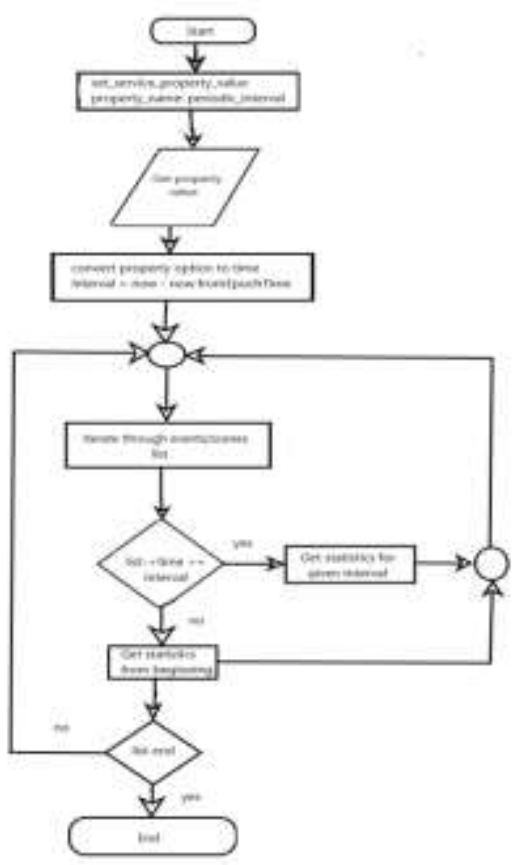

Slika 4. Algoritam dobavljanja statistike u jedinici vremena

\section{REZULTATI RADA}

Verifikacija rada se vrši pomoću skripte napisane $u$ interpreteru skripti koja je dodata u postojeće programsko rješenje. U cilju verifikacije rada pokrenuta je klijentska aplikacija u kojoj je kreirana scena koja će se aktivirati kad se otvori ili zatvori senzor vrata. Korištena je i pametna utičnica, čije je stanje mijenjano ručno.

U tabeli 1 prikazan je ciklus ispitivanja i verifikacije rada sistema. Tabela prikazuje opis izvršenih testova i njihove rezultate.

Tabela 1. Prikaz izvršenih testova i njihovih rezultata

\begin{tabular}{|c|c|}
\hline Test & Rezultat \\
\hline $\begin{array}{c}\text { Dobavljanje inicijalnog } \\
\text { broja promjena uređaja i } \\
\text { scena u sistemu }\end{array}$ & PROŠAO \\
\hline $\begin{array}{c}\text { Ispis trenutnog broja } \\
\text { promjena stanja uređaja i } \\
\text { scena u zadatom } \\
\text { vremenskom intervalu od } \\
15 \text { minuta }\end{array}$ & PROŠAO \\
\hline
\end{tabular}

\begin{tabular}{|c|c|}
\hline $\begin{array}{c}\text { Ispis statistike u periodu } \\
\text { mirovanja sistema sa } \\
\text { zadatim intervalom od } 15 \\
\text { minuta }\end{array}$ & PROŠAO \\
\hline $\begin{array}{c}\text { Ispis trenutnog broja } \\
\text { promjena stanja uređaja i } \\
\text { scena u zadatom } \\
\text { vremenskom intervalu od } \\
30 \text { minuta }\end{array}$ & PROŠAO \\
\hline $\begin{array}{c}\text { Ispis statistike u periodu } \\
\text { mirovanja sistema sa } \\
\text { zadatim intervalom od } 30 \\
\text { minuta }\end{array}$ & PROŠAO \\
\hline $\begin{array}{c}\text { Ispis statistike od početka } \\
\text { rada sistema }\end{array}$ & PROŠAO \\
\hline
\end{tabular}

\section{LITERATURA}

[1] Home Automation System, URL https://www.techopedia.com/definition/29999/homeautomation-system, September 2018.

[2] A Data Acquisition and Control System in Smart Home Based on the Internet of Things, Zhubing $\mathrm{Hu}$, Chengde Petroleum College, 2016.

[3] S. Suresh and P. V. Sruthi, "A review on smart home technology," in 2015 Online International Conference on Green Engineering and Technologies (IC-GET), Nov 2015, pp. 1-3.

[4] A Smart Home Gateway Platform for Data Collection and Awareness, Pan Wang, Feng Ye, Member, IEEE, Xuejiao Chen

[5] S. Guoqiang, C. Yanming, Z. Chao, and Z. Yanxu, "Design and implementation of a smart iot gateway," in 2013 IEEE International Conference on Green Computing and Communications and IEEE Internet of Things and IEEE Cyber, Physical and Social Computing, Aug 2013, pp. 720-723.

[6] P. Wang, S. Y. Zhang, and X. J. Chen, "Sfarima: A new network traffic prediction algorithm", in 2009, First International Conference on Information Science and Engineering, Dec 2009, pp. 1859-1863

\section{Kratka biografija:}

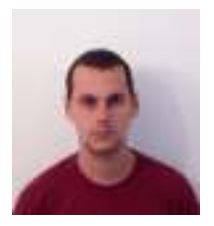

Dejan Živković rođen je u Derventi 1990. god. Master rad na Fakultetu tehničkih nauka iz oblasti Elektrotehnike i računarstva Računarstvo i automatika odbranio je 2018.god.

kontakt: zivkovicdejan230@gmail.com 